\title{
A Study of College Students' Foreign Language Anxiety in English Learning Based on the Teaching Model of Sheltered Instruction Observation Protocol
}

\author{
Chenhua Wei \\ Guangxi University of Foreign Languages, Nanning 530222, \\ Guangxi, China
}

\begin{abstract}
Foreign language anxiety in English learning has always been a major focus of English teaching research. How to relieve English majors' foreign language anxiety and improve their classroom participation becomes an imperative issue for English teachers. Based on the American teaching model of Sheltered Teaching and Observation Protocol (SIOP), this study explores whether the SIOP teaching model can help relieve English learning anxiety. The experiment on 60 freshmen majoring in business English shows that the SIOP model can relieve students' foreign language learning anxiety and improve their classroom participation. The SIOP teaching model is worth popularizing in business English teaching.
\end{abstract}

Best Evidence in Chinese Education 2022; 10(1):1303-1313.

Doi: 10.15354/bece.22.or010.

How to Cite: Wei, C. (2022). A study of college students' foreign language anxiety in English learning based on the teaching model of sheltered instruction observation protocol. Best Evidence in Chinese Education, 10(1):1303-1313.

Keywords: SIOP Teaching Model, Foreign Language Anxiety, College Students, English Learning, Business English 
Wei. College Students' Foreign Language Anxiety in English Learning.

Correspondence to: Chenhua Wei, Guangxi University of Foreign Languages, A-19 Wuhe Avenue, Nanning 530222, Guangxi, China.E-mail:649008927@qq.com

(C) 2022 Insights Publisher. All rights reserved.

(c) (i) (8) Creative Commons Non Commercial CC BY-NC: This article is distributed under the terms of the Creative Commons Attribution-NonCommercial 4.0 License

(http://www.creativecommons.org/licenses/by-nc/4.0/) which permits non-commercial use, reproduction and distribution of the work without further permission provided the original work is attributed by the Insights Publisher. 


\section{Introduction}

I $\mathrm{N}$ recent years, many language colleges and universities have set up business English major and business English teaching and research has been paid increasing attention. The study of business English is different from that of other English majors, because business English students need to master not only the Basic English language but also the relevant professional knowledge of business and trade, as well as the business culture of different countries. Business English majors who study in local application-oriented universities are educated with more explicit objectives. The importance of students' practical abilities and English language competence as well as their business knowledge is emphasized so that students can serve the local economic and social development after graduation. However, at present, the teaching mode of business English is relatively simplified. Teachers are the dominators in the classroom while students' role as the pro-active learners has not been highlighted, which is disadvantageous for students' active learning and the internalization of subject knowledge. As a result, students are prone to lack of enthusiasm in English learning because of the long-term monotonous and rigid teaching mode, which compromises their participation in the classroom and confidence in foreign language learning. As English is not their mother tongue, once they lose interest in it which they have to learn, they will unconsciously gain foreign language learning anxiety. This is an important issue that foreign language teachers should not dodge. Anxiety is a common phenomenon in foreign language learning in China, and is one of the key psychological variables in language learning (Wang \& Wan, 2001).

The American Sheltered Instruction Observation Protocol (SIOP) teaching model is based on the input hypothesis of Krashen's language acquisition theory, Swain's output hypothesis and Cummins' Common Underlying Proficiency (CUP) hypothesis (August \& Shanahan, 2006). According to August and Shanahan, the possibility of foreign language learning lies in the fact that the cognitive ability in native language learning can be transferred to second language learning, resulting in the deep sharing of cognitive ability. They insist that the effect of classroom teaching depends on the deep sharing of input language content and on the comprehensibility and interest of input language content and there is a close relationship between language knowledge acquisition and skill acquisition. Other researchers confirmed that the SIOP model is of high reliability and validity (Echevarria, 2007). It focuses on the subject contents, and various sheltering teaching strategies are flexibly used in teaching to combine the learning of subject knowledge with the cultivation of language competence.

One of the major functions of the SIOP model is to alleviate students' anxiety caused by their incompetence in using English. The application of sheltered teaching strategies such as cooperative learning, group learning and peer guidance aims at creating a non-threatening participation classroom environment for students so that they can participate more confidently in English classroom. Students with different language proficiency and cultural background will help one another in group work or even across groups. And in such a friendly environment, they are definitely more confident and participating in class activity (Yin, Wang, \& Zhao, 2020). Business English majors aim for both business-related knowledge and English language proficiency in the courses of comprehensive business English, and the SIOP teaching model is aligned with such teaching requirements. This study explores effectiveness of SIOP model in business 
English teaching, focusing on whether SIOP model can help ease students' foreign language anxiety and improve their classroom participation.

\section{A Brief Introduction to Sheltered Instruction Obser- vation Protocol (SIOP)}

\section{Definition}

The Sheltered Instruction Observation Protocol was developed by researchers at the Center for Research on Education, Diversity \& Excellence (Short, 2013). It is a validated model of sheltered instruction, which helps teachers plan and deliver lessons that enable learners to develop their English while acquiring academic knowledge. This model makes it easier for students to understand the professional contents in courses taught in English through various teaching strategies and improves students' academic English at the same time (Echevarria \& Graves, 2007). The model is called sheltered teaching because various strategies are constantly used to embellish the teaching. A non-threatening sheltered language environment are created for the students; Classroom teaching conforms to English learners' language level, which makes the teaching contents easier to be understood and accepted (August \& Shanahan, 2006).

The "decoration" in this teaching model includes providing students with various diagrams, extensive supplementary materials and adapted course content suitable to students' language ability. Meantime, students' listening, speaking, reading and writing skills are honed in interactive and meaningful classroom activities based on scaffolding teaching. What's more, student's critical thinking is developed in discussion, questioning and argument in a non-threatening sheltered learning environment, thanks to cooperative learning, group study and peer guidance (Echevarria et al., 2004).

\section{Components}

Eight components are included in the SIOP Model, that is, lesson preparation, background building, comprehensible input, strategy implementation, class interaction, practice and application, lesson delivery, review, and assessment. Each part is equipped with corresponding teaching strategies with elaborations on concrete operation methods as well as teaching evaluation. At the stage of lesson preparation, teachers should explain learning objectives of the course to students clearly to stimulate students' enthusiasm and initiative. It is emphasized that the contents of the course should be aligned with the students' language ability and educational background, and various teaching aids can be used to help students better understand the contents. At the stage of background building, teachers can help students to connect the existing knowledge with the new knowledge, that is, to transfer the existing knowledge and skills in their mother tongue to English learning, to make them think coherently and critically. This process helps students form their own views and perspectives. At the stage of strategy implementation, students are provided with sufficient opportunities to implement a variety of learning strategies, such as cognitive, communicative, emotional learning strategies. With the help and guidance of scaffolding teaching, students' ability of independent thinking and problem-solving can be gradually developed. At the stage of interaction 
and application, students are given enough time to think, read, speak, and write. All students are encouraged to participate actively in discussion. Teachers also provide relevant teaching materials or tools to enable students to use their language in group discussions and collaborative activities, to improve their critical thinking and verbal expression. At the stage of review and assessment, teachers evaluate students' performance by observing their classroom interaction and participation in class activities, and also provide timely feedback to individual students for self-reflection (Wu, 2014). SIOP teaching concepts are consistent with the trends of foreign language teaching in China, providing reference for teachers in improving their bilingual teaching skills and implementing English teaching reform. Further efforts are required to localize SIOP teaching model.

\section{Foreign Language Anxiety}

According to Horwitz, Horwitz, and Cope (1986), foreign language anxiety is not just a complex emotion derived from fear of foreign language learning, but rather a conceptually distinct variable in foreign language learning related to students' self-concept, beliefs, emotions, and behaviors. Numerous empirical studies indicate that anxiety has a negative impact on language learning and is also a major factor affecting foreign language learning initiative and achievement. Horwitz, Horwitz, and Cope conducted a study and identified three major factors affecting students' anxiety in foreign language classes, that is, communication anxiety, test anxiety and fear of negative evaluation from classmates and teachers. Based on their study, foreign language classroom anxiety scale (FLCAS) was developed to measure the breadth and depth of foreign language anxiety. FLCAS standardized the measurement of language learning anxiety (Guo \& $\mathrm{Xu}, 2014)$. Since then, teachers worldwide have applied FLCAS to conduct research on foreign language learning anxiety. Many studies show that most foreign language learners have experienced significant foreign language anxiety (FLA), and foreign language learning anxiety has a negative impact on students' foreign language performance (Dewaele \& Thirtle, 2009; Dogan \& Tuncer, 2016; Horwitz, 2001). Some studies focus on how foreign language anxiety affects students' learning confidence and achievements. In a study of English learners at a London school, Dewaele and Thirtle (2009) gave students two options, either to continue or drop out of foreign language learning. The research showed that students who choose to give up foreign language learning were those who had severe foreign language learning anxiety. Similar results were found in the research by Doğan and Tuncer (2016). They carried out a correlational study to investigate the relationship between foreign language classroom anxiety and foreign language achievement. Participants were engineering students from Turkish universities studying English-required courses. FLCAS was adopted throughout the research and the results showed that there is a negative correlation between classroom anxiety and foreign language achievement.

In China, current research focuses on whether students' foreign language anxiety can be alleviated under different teaching models. Huang (2021) conducted a study on 210 English students in one semester by means of longitudinal case study, questionnaire survey, and interviews, and reached the results that the use of Flipped Classroom teaching model can significantly alleviate the overall classroom anxiety, expression 
anxiety and classroom teaching anxiety, and increase students' confidence in their use of language. Tao and He (2021) conducted a survey of foreign language anxiety among 108 Chinese students and 72 Mexican students in English class from the perspective of language distance and the results showed that Chinese EFL learners have higher foreign language anxiety than Mexican EFL learners. It means that the higher cognitive decoding effort is required for second language learners who have greater language distance. At present, research on the correlation between foreign language anxiety of college English majors and the SIOP teaching model is insufficient in China. It is hoped that this paper will inspire more research on this topic.

\section{Methodology}

\section{Research Questions}

This study tries to answer the following two questions: i) whether the students' foreign language anxiety can be relieved under the SIOP teaching model; ii) Whether business English majors' classroom participation can be improved under this model.

\section{Participants}

Two classes of students, a total of sixty business English majors in Guangxi University of Foreign Languages participated in the study. One of the classes is the experimental class and the other is the control class. Each class has 30 students.

\section{Research Methods and Instruments}

\section{Methods}

The method of quasi-experimental designs is used in this study. The independent variable is the teaching design and implementation of comprehensive courses for business English majors under the SIOP model; the corresponding dependent variables are business English majors' foreign language learning anxiety and students' classroom participation. In this study, both experimental and control class were taught by the same teacher. In addition, the study tried to avoid the influence and interference of nonexperimental factors by ensuring that the two selected classes have the same teaching hours and the same teaching materials. And the only variable experimental factor was different teaching modes: The experimental class was taught with the SIOP teaching model while the control class with the conventional language teaching mode, to examine the effects of the experimental factor on business English majors' English anxiety and classroom participation. The following measures were implemented to guarantee the reliability and validity of this experiment.

\section{Reliability}

After questionnaire A was finalized, the reliability was tested in a small scope by retest method. Questionnaire A was retested in 30 students, andowas 0.87, which met the standard requirement. In the process of questionnaire design and implementation, the 
following measures were taken to ensure the reliability of the questionnaire: (i) The number of questions should be as small as possible and limited to one page; (ii) The language should be as plain and concise as possible. The majority of questions are multiple-choice ones, with a few blank-filling ones; (iii) Anonymous filling in the questionnaires; (iv) Handing out and filling in the questionnaires without teachers' presence.

\section{Validity}

After the design of questionnaire, experts were asked to decide whether the questionnaire can cover the research topic and whether it is suitable for the validity test, and the rate of expert identification is $91.72 \%$.

As for questionnaire B, FLCAS has been proved to be of high reliability and validity in many years of teaching and research.

\section{Instruments}

Questionnaire A: the Classroom Participation Questionnaire for Business English Majors (the questionnaire is designed to serve research purposes); Questionnaire B: FLCAS developed by E. K. Horwitz, M.B. Horwitz, and J. Cope. FLCAS was compiled in 1986 focusing on communication anxiety, test anxiety and negative evaluation anxiety.

\section{Procedure}

This teaching experiment covers three stages. At the first stage, the students of selected classes (experimental class and control class) were asked to fill in the questionnaire A before the implementation of the SIOP teaching model. At the second stage, the two selected classes were taught in different teaching modes. In the experimental class, the SIOP teaching model was integrated with regular teaching so that the SIOP's sheltering strategies were flexibly applied in the whole teaching process according to the teaching contents of specific units and students' learning situation. At this stage, the construction of pre-class background knowledge and the input of comprehensible business knowledge were key tasks. Effective classroom activities were designed to stimulate students' desire for exploration and autonomous learning, which ensure the acquisition of business knowledge and English language competence. In the control class, however, the teaching mode remained conventional. At the third stage, Questionnaire A and questionnaire B were distributed to two selected classes (experimental class and control class) for the second time, to verify the influence of experimental factor in this study: Whether the SIOP model can relieve the students' foreign language anxiety and improve the students' classroom participation.

\section{Data Collection}

Questionnaire A and questionnaire B were distributed and collected in the classes of comprehensive business English and the key instructions were explained clearly to ensure the validity of data. 120 questionnaires were distributed, and 120 questionnaires 
were collected, which was conducted from October 2020 to December 2020. All statistics and analyses were treated by software SPSS17.

\section{Results and Discussion}

\section{The SIOP Model can Relieve the Foreign Language Anxiety of Business Eng- lish Students.}

According to the data collected after the first stage (Table1), there was no significant difference in students' English learning anxiety between the two selected classes before adopting different teaching modes. As shown in table 1 , differences in test anxiety $(\mathrm{t}=$ 1.345) and negative evaluation anxiety $(\mathrm{t}=-1.321)$ between the experimental and the control classes were very slight, though the difference in communication anxiety $(\mathrm{t}=$ $3.328, \mathrm{MD}=0.35^{*}$ ) was noticeable. Overall, the foreign language anxiety levels of the two classes were roughly the same. However, the data and sequential analysis at the third stage (Table 2) showed great differences in the anxiety level. After the experiment, that is, after the SIOP teaching model implemented, there were significant differences between the two classes in the three factors related to foreign language learning anxiety: communication anxiety $(\mathrm{t}=5.873)$, test anxiety $(\mathrm{t}=7.021)$ and negative evaluation anxiety $(\mathrm{t}=5.408)$. Meanwhile, foreign language anxiety of the experimental class was significantly alleviated: communication anxiety $(\mathrm{MD}=0.61 *)$, test anxiety $(\mathrm{MD}=$ $\left.0.89^{*}\right)$ and negative evaluation anxiety $\left(\mathrm{MD}=0.47^{*}\right)$.

The above data indicate that the application of the SIOP model can alleviate students' foreign language learning anxiety in the comprehensive business English courses. The figures of the experimental class in terms of communication anxiety, test anxiety and negative evaluation anxiety were significantly smaller than those of the control class, indicating the experimental class experienced a significant decrease in foreign language anxiety after the SIOP teaching, while the control class underwent increased foreign language anxiety.

Under the SIOP teaching model, thanks to the effective pre-class input, class activities and after-class review, the students' language ability and communication skills in the experimental class were trained in a better way, and their business knowledge was more easily acquired. As a result, their self-confidence and selfconsciousness in learning were improved, and their foreign language anxiety in business English learning decreased significantly. Therefore, the application of the SIOP teaching model in business English teaching can alleviate students' foreign language anxiety.

\section{SIOP Model is Helpful to Improve Business English Students' Classroom Par- ticipation}

Comparative analysis of the data in Table $\mathbf{3}$ indicates that the experimental class had slightly higher participation than the control class $\left(\mathrm{MD}=0.25^{*}\right)$ before the application of the SIOP teaching model, yet the difference was not significant.

There were significant differences in student's classroom participation ( $\mathrm{T}=$ 4.789, $\mathrm{DF}=96, \mathrm{p}<0.05)$ between the experimental class and control class after adaptation. The experimental class $\left(\mathrm{MD}=0.65^{*}\right)$ had significantly higher participation than 
Table 1. A Comparison of English Language Anxiety between Experimental and Control Classes at the First Stage.

\begin{tabular}{lllllllll}
\hline & Class & N & Mean & SD & t & df & Sig. & MD \\
\hline $\begin{array}{l}\text { Communication } \\
\text { Anxiety }\end{array}$ & Control & 30 & 2.7473 & 0.53251 & -3.328 & 96 & 0.001 & -0.35254 \\
\cline { 2 - 5 } & Experimental & 30 & 3.2167 & 0.50023 & & & & \\
\hline $\begin{array}{l}\text { Test } \\
\text { Anxiety }\end{array}$ & Control & 30 & 2.4832 & 0.74864 & -1.345 & 96 & 0.149 & -0.23021 \\
\cline { 2 - 5 } $\begin{array}{l}\text { Exgative } \\
\begin{array}{l}\text { Evaluation } \\
\text { Anxiety }\end{array}\end{array}$ & Control & 30 & 2.8715 & 0.40535 & -1.321 & 96 & 0.155 & -0.12516 \\
\cline { 2 - 5 } & Experimental & 30 & 3.0206 & 0.45012 & & & & \\
\hline
\end{tabular}

Table 2. A Comparison of English Language Anxiety between Experimental and Control Classes at the Third Stage.

\begin{tabular}{|c|c|c|c|c|c|c|c|}
\hline & Class & $\mathbf{N}$ & Mean & $t$ & df & Sig. & MD \\
\hline \multirow{2}{*}{$\begin{array}{l}\text { Communication } \\
\text { Anxiety }\end{array}$} & Control & 30 & 3.5534 & \multirow{2}{*}{5.873} & \multirow{2}{*}{96} & \multirow{2}{*}{0.000} & \multirow{2}{*}{0.61061} \\
\hline & Experimental & 30 & 3.0316 & & & & \\
\hline \multirow{2}{*}{ Test Anxiety } & Control & 30 & 3.5353 & \multirow{2}{*}{7.021} & \multirow{2}{*}{96} & \multirow{2}{*}{0.000} & \multirow{2}{*}{0.89897} \\
\hline & Experimental & 30 & 2.6336 & & & & \\
\hline \multirow{2}{*}{$\begin{array}{l}\text { Negative } \\
\text { Feedback } \\
\text { Anxiety }\end{array}$} & Control & 30 & 3.3020 & \multirow{2}{*}{5.408} & \multirow{2}{*}{96} & \multirow{2}{*}{0.000} & \multirow{2}{*}{0.47816} \\
\hline & Experimental & 30 & 2.8162 & & & & \\
\hline
\end{tabular}

Table 3. A Comparison of Classroom Participation between Experimental and Control Classes at the First Stage.

\begin{tabular}{lllllllll} 
Classroom & Class & $\mathrm{N}$ & Mean & $\mathrm{SD}$ & $\mathrm{t}$ & $\mathrm{df}$ & Sig. & MD \\
\cline { 2 - 7 } Participation & Contrast & 30 & 2.6113 & 0.70521 & \multirow{2}{*}{-2.076} & 81.306 & 0.0 .30 & -0.25134 \\
\cline { 2 - 5 } & Experimental & 30 & 2.8432 & 0.43103 & & &
\end{tabular}

Table 4. A Comparison of Classroom Participation between Experimental and Control Classes at the Third Stage.

\begin{tabular}{lllllllll} 
Classroom & Class & N & Mean & SD & t & df & Sig. & MD \\
\cline { 2 - 6 } Participation & Contrast & 30 & 2.6032 & 0.63564 & \multirow{2}{*}{-4.789} & \multirow{2}{*}{96} & 0.000 & -0.65138 \\
\cline { 2 - 5 } & Experimental & 30 & 3.2751 & 0.70663 & & & & \\
\hline
\end{tabular}


the control class (Table 4). In addition, if we compare the data vertically, we can find that there are remarkable differences between the two classes before and after the reform of teaching modes. On the average, after a semester's SIOP teaching, the students' participation of the experimental class has increased significantly, whereas the control class did not show remarkable changes. Therefore, the results prove that the application of SIOP teaching model can effectively improve the classroom participation of business English majors.

\section{Conclusion}

Comparative analysis of the above data revealed that students' foreign language anxiety in the experimental class has been alleviated in that semester because of the application of the SIOP teaching model, and those students have also made great progress in their classroom participation. In contrast, the foreign language anxiety of the control class was not relieved under the conventional teaching mode, and the students' classroom participation also remained unchanged, though the two classes were taught by the same teacher, with the same teaching materials and the same teaching time. Thus, this teaching experiment well answers the two questions we set at the beginning of this research. The SIOP teaching model helps relieve business English students' foreign language anxiety and improve their classroom participation. Business English majors can better decode the course contents through relevant learning skills from the SIOP model. Moreover, the repetitive use of SIOP teaching strategies not only enables students to master the declarative knowledge of the subjects, but also develop their language learning skills, curriculum learning strategies and critical thinking (Wu, 2015).

In the context of new liberal arts construction in China, the reform of foreign language education is constantly advancing. In the SIOP teaching model, foreign language teaching can be integrated with knowledge of specialties. While facilitating students' acquisition of the specialized knowledge of the relevant subjects, it can also expand their horizon, and cultivate their cross-cultural competence and global vision. In this model, listening, speaking, reading, writing and translation are treated as a natural and holistic learning process to improve the students' language proficiency (Yuan, 2011). When the SIOP model is applied in business English teaching, it can effectively improve the business English majors' confidence in foreign language learning, foreign language proficiency and comprehensive competence.

There are several limitations to the current study. First, as the sample size is small, the statistical power of the analysis is limited. Second, after completion of this teaching experiment, the researcher did not follow up the 60 Business English majors, and the level of foreign language anxiety in the control class may change to some extent. Therefore, based on the results of this study, the curriculum design and implementation of the SIOP model in business English teaching will be further improved in the followup experimental research. 


\section{References}

August, D., \& Shanahan, T. (2006). Developing literacy in second-language learners: Report of the national literacy panel on languageminority children and youth. Center for Applied Linguistics, Lawrence Erlbaum Associates: Mahwah, NJ.

Dewaele, J., \& Thirtle, H. (2009). Why do some young learners drop foreign languages? A focus on learner-internal variables. International Journal of Bilingual Education and Bilingualism, 2009(12): 635-649. DOI: https://doi.org/10.1080/13670050802549656

Dogan,Y., \& Tuncer, M. (2016). Examination of foreign language classroom anxiety and achievement in foreign language in Turkish university students in terms of various variables. Journal of Education and Training Studies, 2016(4): 18-29. DOI: http://dx.doi.org/10.11114/jets.v4i5.1337

Echevarria, J., \& Graves, A. (2007) Sheltered content instruction: Teaching English leaners with diverse abilities. New York: Pearson.

Echevarria, J., Vogt, M., \& Short, D. (2004). Making content comprehensible for English learners: The SIOP model (2nd Edition). Boston: Allyn \& Bacon.

Guo, Y., \& Xu, J.F. (2014). A multidimensional study on English learning anxiety of nonEnglish majors. Foreign Language World, 2014(4):2-10.

Horwitz, E.K. (2001). Language anxiety and achievement. Annual Review of Applied Linguistics, 21:112-126. DOI: https://doi.org/10.1017/S0267190501000071

Horwitz, E.K., Horwitz, M.B., \& Cope, J. (1986). Foreign language classroom anxiety. The Modern Language Journal, 70(2):125-132.
DOI: http://dx.doi.org/10.1111/j.15404781.1986.tb05256.x

Huang, D.M. (2021). An empirical study on the effect of flipped classroom on college students' English learning anxiety. Journal of PLA University of Foreign Language, 2021(9):26-32.

Short, D. (2013). Training and sustaining effective teachers of sheltered instruction. Theory Into Practice, 2013(52):118-127. DOI: https://doi.org/10.1080/00405841.2013.7703 $\underline{29}$

Tao, J.F., \& He, Z.M. (2021). Foreign language anxiety and causal orientation of language learning difficulties. Foreign Language Research, 2021(2):78-83.

Wang, Y.Q., \& Wan, Y.S. (2001). Foreign language anxiety and its impact on foreign language learning. Foreign Language Teaching and Research, 2001(2):122-126.

$\mathrm{Wu}$, S.S. (2014). On the enlightenment of American SIOP model to bilingual teacher education in China. Shanxi Education, 2014(10):43-45.

Wu, S.S. (2015). American SIOP model and the development of critical thinking ability of Chinese foreign language majors. Foreign Language Education, 36(4):60-63

Yin, H., Wang, M.J., \& Zhao, J.H. (2020). An empirical study on the application of SIOP model for English teaching in universities for nationalities. New West, 2020(18):3.

Yuan, P.H. (2011). Immersion bilingual education in the University of Ottawa and its implications for college English teaching in China. Foreign Language World, 2011(4):75-82.

Received: 14 December 2021

Revised: 21 December 2021

Accepted: 04 January 2022 